"This document is the Accepted Manuscript version of a Published Work that appeared in final form in The Journal of Physical Chemistry A, copyright $\odot$ American Chemical Society after peer review and technical editing by the publisher. To access the final edited and published work see https://pubs-acs-org.uml.idm.oclc.org/doi/10.1021/acs.jpca.9b08681.

\title{
Internal Motions and Sulfur Hydrogen Bonding in Methyl 3- Mercaptopropionate
}

\author{
Weslley G. D. P. Silva, ${ }^{\text {a }}$ Luca Evangelisti, ${ }^{b}$ Jennifer van Wijngaarden ${ }^{a^{*}}$ \\ a Department of Chemistry, University of Manitoba, Winnipeg, Manitoba R3T 2N2, Canada \\ bDepartment of Chemistry “G. Ciamician”, University of Bologna, Via Selmi 2, I-40126 \\ Bologna, Italy
}

*Corresponding author: vanwijng@umanitoba.ca 


\begin{abstract}
The effect of sulfur hydrogen bonding on the conformational equilibrium of methyl 3-mercaptopropionate was investigated using microwave spectroscopy in a supersonic jet expansion. The two most stable conformers (I and II) were assigned in the rotational spectra and complex splitting patterns owing to the methyl internal rotation and $\mathrm{SH}$ tunneling motion were resolved and analyzed in detail. For both conformers, the experimental torsional barriers for the methyl top are similar and of about $5.1 \mathrm{~kJ} \mathrm{~mol}^{-1}$, which reveal that their geometrical differences do not affect the methyl internal rotation. The experimentally-derived rotational and centrifugal distortion constants, along with the methyl internal rotation barriers are discussed in detail and compared with results from density functional theory and ab initio calculations. Quantum theory of atoms in molecules, non-covalent interactions, and natural bond orbital analyses show that the global minimum geometry (I), which has the thiol hydrogen oriented towards the carbonyl of the ester, is stabilized by an $\mathrm{SH}^{\cdots} \mathrm{O}=\mathrm{C}$ hydrogen bond. The presence of a hydrogen bond is confirmed by the derivation of an accurate experimental geometry that reveals a hydrogen bond distance and angle S-H-O of $2.515(4) \AA$ and $117.4(1)^{\circ}$, respectively. These results are key benchmarks to expand the current knowledge of sulfur hydrogen bonds and the relationship between internal motions and conformational preferences in esters.
\end{abstract}




\section{Introduction}

The laudable goal of developing an improved understanding of structural, energetic and physical characteristics of non-covalent interactions has driven a range of recent experimental and theoretical studies. ${ }^{1-3}$ This is due to the importance of such interactions in molecular recognition, for example, which directs chemical, biological, and technological processes. ${ }^{2,4}$ For many decades, hydrogen bonding (HB) has been known to be the principal effect that governs the three dimensional structures of proteins, organic and organometallic molecules, and play a key role in the modulation of important reaction pathways. ${ }^{5,6}$ Consequently, the nature of HBs has motivated numerous scientific investigations but these have mainly focused on strong HBs formed by oxygen and nitrogen, while much less attention has been devoted to weak interactions, such as the ones involving sulfur. Sulfur HBs are dispersive in nature, and due to their strength, it had been assumed that they are not the key factor that determines the structures of S-containing molecules. However, recent experiments have highlighted the influence of sulfur $\mathrm{HBs}$ in ruling processes and conformational preferences, such as the determination of the secondary structures of proteins. ${ }^{4}$ Consequently, benchmarking, characterizing, and understanding the nature of sulfur HBs are of increasing interest in the literature. ${ }^{7-9}$ As recently reviewed by Biswal, ${ }^{4}$ many systems still need to be experimentally analyzed in order to correctly address the nature, strength, and directionality of sulfur interactions.

Important initial steps in the characterization of non-covalent interactions involve determining the structures of model systems and establishing their relative stabilities using spectroscopic techniques along with computational methods. When it comes to interactions with low binding energies, such as sulfur HBs, the experimental elucidation becomes challenging as the interactions are easily disrupted depending on the physical state or solvent, for example. Fourier transform microwave (FTMW) spectroscopy is a useful approach to address the dearth of 
experimental data in the literature on weak non-covalent interactions as the molecules are interrogated in the gas phase in a collision-free supersonic jet expansion isolated from crystal packing and solvent effects. ${ }^{2}$ Hence, the FTMW technique is a powerful method for the accurate determination of geometrical parameters associated with weak interactions, and for benchmarking purposes as shown by a few recent reports dealing with the characterization of sulfur HBs. ${ }^{7,8,10}$

FTMW studies of S-containing compounds show that sulfur forms a variety of intra- and intermolecular non-covalent interactions in the gas phase, where it can act as a proton donor and/or proton acceptor, as shown for the $\mathrm{S}-\mathrm{H}^{\cdots} \mathrm{S}, \mathrm{S}-\mathrm{H}^{\cdots} \mathrm{O}$, and $\mathrm{S}-\mathrm{H}^{\cdots} \mathrm{O}=\mathrm{C}$ HBs in the $\mathrm{H}_{2} \mathrm{~S}$ dimer, ${ }^{7}$ monohydrated clusters of furfuryl mercaptan, ${ }^{8}$ and in the monomer of 3-mercaptopropionic acid, ${ }^{10}$ respectively. In the latest study, the biologically important interaction between a thiol and a carbonyl group has been proven for the first time in the gas phase, where the importance of this interaction in ruling the conformational equilibrium of the investigated compound was highlighted.

A related molecule for the study of intramolecular $\mathrm{S}-\mathrm{H} \cdots \mathrm{O}=\mathrm{C}$ HBs is methyl 3-mercaptopropionate [HS- $\mathrm{CH}_{2}-\mathrm{CH}_{2}-(\mathrm{C}=\mathrm{O})-\mathrm{O}-\mathrm{CH}_{3}$. The presence of a methyl group in the ester version can lead to complex splitting patterns in the rotational spectrum which also makes this molecule a prototype system for the investigation of methyl internal rotation barriers $\left(V_{3}\right)$ in esters and for probing the relationship between $V_{3}$ and conformational preference. ${ }^{11-13}$ For thioacetic acid, ${ }^{11}$ for example, the anti conformation has an experimental $V_{3}$ barrier that is approximately five times larger than the syn one mainly due to both steric repulsion and conjugative effects. In contrast, conformational differences in the cis and trans conformers of 5-methyl furfural ${ }^{14}$ were shown to not play a role in the barriers for the methyl internal rotor. Determining the experimental $V_{3}$ in a variety of systems is often difficult but necessary for the development of improved methodologies to accurately model the spectra and dynamics of molecules in the gas phase and 
beyond. For large, flexible molecular systems that adopt multiple conformations, ${ }^{11}$ such as methyl 3-mercaptopropionate, understanding the effects that govern the $V_{3}$ barriers brings more challenges since their values can be a result of the competition between steric hindrance, electronic delocalization, and conformational relaxation.

In this paper, we report the first rotational spectroscopic investigation of methyl 3-mercaptopropionate (3MP) using chirped-pulse and cavity-based FTMW spectroscopy supported by quantum mechanical calculations. The observed spectrum of 3MP is dominated by features that arise from two conformers (I and II) where the lowest energy one (I) is stabilized by an intramolecular $\mathrm{HB}$ involving sulfur. Further insights into the $\mathrm{S}-\mathrm{H}^{\cdots} \mathrm{O}=\mathrm{C}$ HB are provided through the determination of an accurate experimental geometry for conformer I from analyzing the spectra of five heavy atom isotopologues, and from the energies derived from the topological quantum theory of atoms in molecules and non-covalent interaction analyses. The experimental methyl internal rotation barriers for conformers I and II and the conformational influences on their values are analyzed in detail aided by computational models. Together, these results expand the current understanding of both sulfur HBs and the relationship between tunneling motions and conformational preference in the gas phase. 


\section{Computational Details}

Theoretical calculations are first used to identify low-energy conformations and to derive relevant molecular properties, such as rotational constants and dipole moment components, which are crucial for the assignment of the conformers in the rotational spectrum. Based on the principle that each conformation has its unique rotational spectral fingerprint, comparison between experimental and calculated data is used to distinguish among the different species and to confirm the assignments.

For 3MP, forty-one possible geometries were identified using the Merck Molecular Force Field (MMFF94), ${ }^{15}$ implemented in the Marvin Sketch 16.10 .10 program (ChemAxon version 6.1). These geometries were further optimized using the DFT dispersion-corrected B3LYP functional with Becke-Johnson (BJ) damping, named B3LYP-D3BJ,${ }^{16-18}$ and the $a b$ initio secondorder Møller-Plesset (MP2) ${ }^{19}$ perturbation theory method with the aug-cc-pVTZ ${ }^{20}$ basis set. The chosen levels of theory have provided satisfactory results when compared to experimental data for the carboxylic acid analog of $3 \mathrm{MP} .{ }^{10}$ Frequency calculations were also carried out to verify the nature of the stationary points and to derive the electronic energy with zero-point energy (ZPE) corrections and the Gibbs free energies at $298 \mathrm{~K}$. The optimization and frequency calculations led to nine true energy minima with relative energies below $11.0 \mathrm{~kJ} \mathrm{~mol}^{-1}$. These calculations were carried out using the Gaussian 16 revision B. $01^{21}$ software.

Natural bond orbital (NBO), ${ }^{22}$ quantum theory of atoms in molecules (QTAIM), ${ }^{23}$ and noncovalent interaction $(\mathrm{NCI})^{24}$ analyses were performed to visualize and quantify intramolecular interactions in the observed conformers. These were carried out using the NBO 6.0, ${ }^{25}$ AIMAll, ${ }^{26}$ and NCIPLOT ${ }^{27}$ programs, respectively. 


\section{Experimental Section}

The pure rotational spectra of 3MP (Sigma-Aldrich Canada, 98.0\%) were recorded using chirped-pulse (cp) and Balle-Flygare ${ }^{28}$ Fourier transform microwave (FTMW) spectrometers, which have been described in detail previously. ${ }^{29,30}$ Briefly, liquid 3-MP (bp: 327 - 328K/ $1.8 \mathrm{kPa}$ ) was placed into a glass bubbler and neon $(100 \mathrm{kPa})$ was used as a carrier gas to deliver the sample into the spectrometers' high vacuum $\left(\mathrm{P} \sim 10^{-6}\right.$ Torr) chambers through a pulsed nozzle (1 mm diameter). The pressure difference between the sample manifold and the chambers result in a supersonic jet, where the rotational temperature of the sample is cooled down to a few Kelvin favoring low-energy conformers. Initial measurements were performed using the cp-FTMW instrument, where the broadband spectra of the compound were recorded from $8-18 \mathrm{GHz}$ in segments of $2 \mathrm{GHz}$. Final measurements were performed in the same frequency range using the Balle-Flygare FTMW spectrometer which provides better resolution and sensitivity. In this design, the molecular beam is coaxial with the resonator axis and thus, all rotational transitions are split into two Doppler components. The transitions typically have line widths of $\sim 7 \mathrm{kHz}$ (FWHM), while the line positions are determined to within about $\pm 1 \mathrm{kHz}$. 


\section{RESULTS}

The nine conformers of 3MP are depicted in Figure 1, while their Cartesian coordinates are given in Tables S1-S9 in the Supporting Information (SI) file. The calculated relative energies and rotational parameters (rotational constants and dipole moment components) are provided in Table 1 . We report the conformers with relative energies below $11.0 \mathrm{~kJ} \mathrm{~mol}^{-1}$ since only lowenergy conformations are expected to be sufficiently populated in the supersonic jet expansion and consequently, observed in the rotational spectra. The conformers are labeled using Roman numerals, from I to IX which represents their order of stability based on the relative Gibbs free energies $(\Delta G)$ from B3LYP-D3BJ/aug-cc-pVTZ.

The conformational behaviour of 3MP reveals that the geometries adopted by its conformers have C-C-C-S dihedral angles of either approximately $60-70^{\circ}$ or $180^{\circ}$, as exemplified by the structures of I and II in Figure 1, respectively. A similar conformational equilibrium has been recently observed for its carboxylic acid analog, 3-mercaptopropionic acid. ${ }^{10}$ For 3MP, the presence of a methyl group in its structure results in a competitive conformational equilibrium where nine energy minima are significantly populated at room temperature. The three most stable conformers (I, II, and III) closely resemble the ones obtained for its acid analog such that the global minimum geometry has the hydrogen of the thiol group directly oriented towards the carbonyl of the ester. Energy calculations show that the most stable geometry is favored by at least $2.1 \mathrm{~kJ} \mathrm{~mol}^{-1}$ when compared to the remaining conformations. In the case of the higher energy conformations, close relative energies between specific geometries are observed, and their energy orderings and abundances vary depending on the level of theory, as exemplified by the theoretical results obtained for II and III (Table 1). Overall, the predicted rotational parameters for each conformer in the two levels of theory are consistent. 
Based on the fact that the intensity of the rotational transitions depends on the dipole components along the principal axes system and population of the rotational energy levels, populated species with sizeable dipole moments are good candidates to start with the experimental investigations. As all have sufficient dipoles, we focused first on the assignment of rotational transitions belonging to the most stable geometries of $3 \mathrm{MP}$.

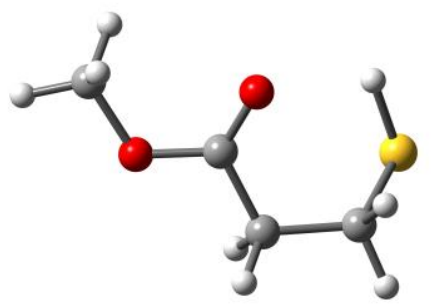

I

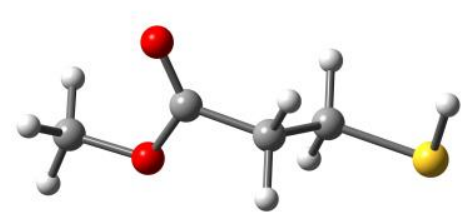

IV

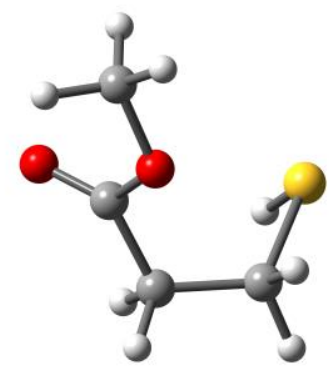

VII

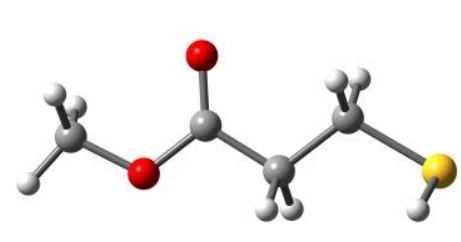

II

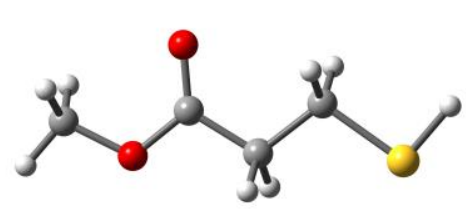

V

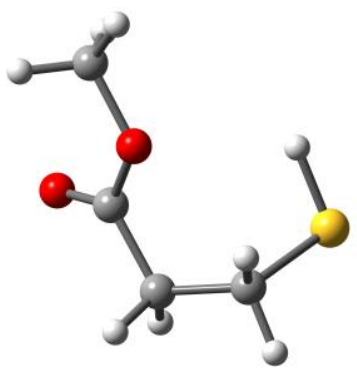

VIII

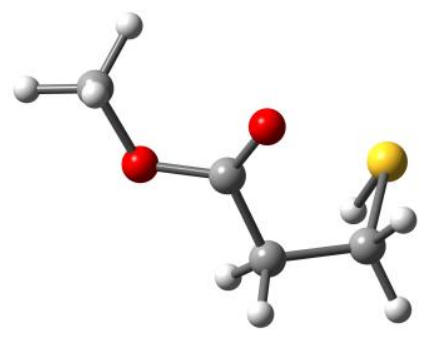

III

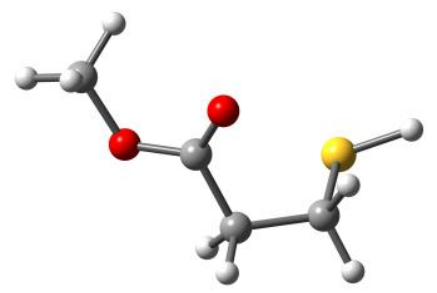

VI

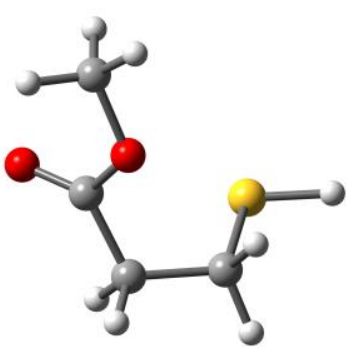

IX

Figure 1. Nine conformers of methyl 3-mercaptopropionate. Carbons, oxygen, sulfur and hydrogen atoms are depicted in grey, red, yellow, and white colours, respectively. 
Table 1. Calculated rotational parameters and relative energies (DFT B3LYP-B3BJ and ab initio MP2, aug-cc-pVTZ) for the conformers of methyl 3-mercaptopropionate.

\begin{tabular}{|c|c|c|c|c|c|c|c|c|}
\hline \multirow[b]{2}{*}{ Conformer } & \multicolumn{4}{|c|}{ B3LYP-D3BJ } & \multicolumn{4}{|c|}{ MP2 } \\
\hline & $A / B / C^{[a]}$ & $\left|\boldsymbol{\mu}_{a}\right| /\left|\boldsymbol{\mu}_{b}\right| /\left|\boldsymbol{\mu}_{c}\right|^{[\mathrm{b}]}$ & $\Delta E_{\mathrm{ZPE}}^{[\mathrm{c}]} / \Delta G^{[\mathrm{d}]}$ & $P\left(\Delta E_{\mathrm{ZPE}}\right)^{[\mathrm{e}]} / P(\Delta G)^{[\mathrm{f}]}$ & $A / B / C^{[\mathrm{a}]}$ & $\left|\boldsymbol{\mu}_{a}\right| /\left|\boldsymbol{\mu}_{b}\right| /\left|\boldsymbol{\mu}_{c}\right|^{[\mathrm{b}]}$ & $\Delta E_{\mathrm{ZPE}}^{[\mathrm{cc}]} / \Delta G^{[\mathrm{d}]}$ & $P\left(\Delta E_{\mathrm{ZPE}}\right) / P(\Delta G)$ \\
\hline I & $5046 / 1055 / 987$ & $2.0 / 1.7 / 0.2$ & $0.0 / 0.0$ & $60.2 / 42.1$ & $4916 / 1093 / 1021$ & $2.0 / 1.9 / 0.2$ & $0.0 / 0.0$ & $61.0 / 44.6$ \\
\hline II & $8256 / 796 / 739$ & $1.8 / 1.6 / 0.6$ & $4.2 / 2.1$ & $11.6 / 18.6$ & $8267 / 806 / 748$ & $1.7 / 1.7 / 0.7$ & $5.0 / 2.9$ & $7.8 / 14.1$ \\
\hline III & $4290 / 1101 / 1055$ & $0.9 / 1.2 / 2.2$ & $4.2 / 2.9$ & $11.2 / 13.0$ & 4099/1172/1107 & $0.6 / 1.2 / 2.5$ & $4.2 / 2.9$ & $11.0 / 14.6$ \\
\hline IV & $5984 / 864 / 796$ & $0.9 / 1.1 / 0.1$ & $7.9 / 3.8$ & $2.4 / 8.8$ & $6025 / 876 / 808$ & $0.8 / 1.1 / 0.2$ & $8.4 / 4.6$ & $2.2 / 7.0$ \\
\hline V & $8160 / 807 / 745$ & $1.3 / 0.5 / 0.0$ & $6.3 / 4.2$ & $2.3 / 3.9$ & $8173 / 819 / 754$ & $1.2 / 0.5 / 0.0$ & $7.1 / 5.0$ & $1.8 / 3.1$ \\
\hline VI & $4163 / 1124 / 1060$ & $0.5 / 0.9 / 1.0$ & $8.4 / 5.4$ & $2.0 / 4.4$ & $3921 / 1219 / 1119$ & $0.0 / 0.8 / 1.1$ & $8.8 / 6.3$ & $2.0 / 3.8$ \\
\hline VII & $3422 / 1295 / 1180$ & $0.2 / 0.2 / 2.1$ & $6.3 / 5.8$ & $4.7 / 4.2$ & $3404 / 1346 / 1232$ & $0.4 / 0.4 / 2.3$ & $5.4 / 5.0$ & $6.8 / 6.0$ \\
\hline VIII & $3483 / 1294 / 1124$ & $0.5 / 0.7 / 2.3$ & $6.3 / 5.8$ & $4.8 / 4.2$ & $3474 / 1331 / 1171$ & $0.4 / 0.6 / 2.6$ & $5.4 / 5.0$ & $6.4 / 5.6$ \\
\hline IX & $3537 / 1249 / 1175$ & $0.1 / 0.8 / 3.1$ & $10.9 / 9.6$ & $0.8 / 0.8$ & $3519 / 1297 / 1231$ & $0.4 / 0.6 / 3.4$ & $10.0 / 9.2$ & $1.0 / 1.2$ \\
\hline
\end{tabular}

${ }^{[\mathrm{a}]}$ Rotational constants $(A, B$, and $C)$ in $\mathrm{MHz} ;{ }^{[\mathrm{b}]}$ Absolute values of the electric dipole moment components in $\mathrm{D}$; ${ }^{[\mathrm{c}]}$ Relative energies with respect to the global minimum accounting for zero-point energy (ZPE) corrections in $\mathrm{kJ} \mathrm{mol}^{-1}$; ${ }^{[\mathrm{d}]}$ Relative Gibbs free energies with respect to the global minimum calculated at $298 \mathrm{~K} \mathrm{in} \mathrm{kJ} \mathrm{mol}^{-1}$; ${ }^{[\mathrm{e}]}$ Population based on the relative energies with $\mathrm{ZPE}$ correction in $\%$; ${ }^{[\mathrm{f}]}$ Population based on the relative Gibbs free energies in \%. 
To identify conformers in the rotational spectrum, we used the predicted data from Table 1 to obtain a simulated spectrum for each using the PGOPHER program. ${ }^{31}$ Initial study of the cpFTMW broadband spectrum led to the identification of two sets of R-branch $a$ - and $b$-type rotational transitions belonging to two different conformers suggesting that the carriers are species with significant values of $\left|\mu_{\mathrm{a}}\right|$ and $\left|\mu_{\mathrm{b}}\right|$. To confirm the quantum number assignments and predict related transitions for each, initial fits were carried out using the PGOPHER program. By comparing the experimental rotational constants with the calculated ones in Table 1, the assigned transitions were attributed to the parent species of conformers I and II which both have sizeable $\left|\mu_{\mathrm{a}}\right|$ and $\left|\mu_{\mathrm{b}}\right|$ dipole components. Additional measurements were carried out using the cavity-based FTMW spectrometer to record transitions with higher resolution and sensitivity. Despite accurate line positions, no $c$-type transitions could be assigned in the spectra of I and II which is consistent with the small predicted values of $\left|\mu_{\mathrm{c}}\right|$.

The cavity-based spectra observed for the parent species of both conformers show complex patterns due to the A/E splitting of the methyl internal rotor. Surprisingly, for the less intense set of transitions, attributed to II, additional splitting ascribed to a torsional motion of the SH group around the C-C-S-H dihedral angle was also observed. We describe the methyl top and SH tunnelling motions in detail below. For conformer I, the intensities of the transitions were sufficient to proceed with the identification of the rotational transitions of its singly substituted ${ }^{34} \mathrm{~S}$ and all four ${ }^{13} \mathrm{C}$ isotopologues in natural abundance. The spectra of the minor isotopes also exhibit the complex $\mathrm{A} / \mathrm{E}$ splitting pattern which is analogous to the pattern observed for the parent species of I. A sample of the broadband spectrum illustrating some assigned rotational transitions for the parent species of both conformers and for the isotopic species of $\mathbf{I}$ is presented in Figure 2. Two 
specific $a$-type transitions showing the very different splitting patterns observed for the parent species of $\mathbf{I}$ and $\mathbf{I I}$ using the Balle-Flygare instrument are shown in Figure 3.

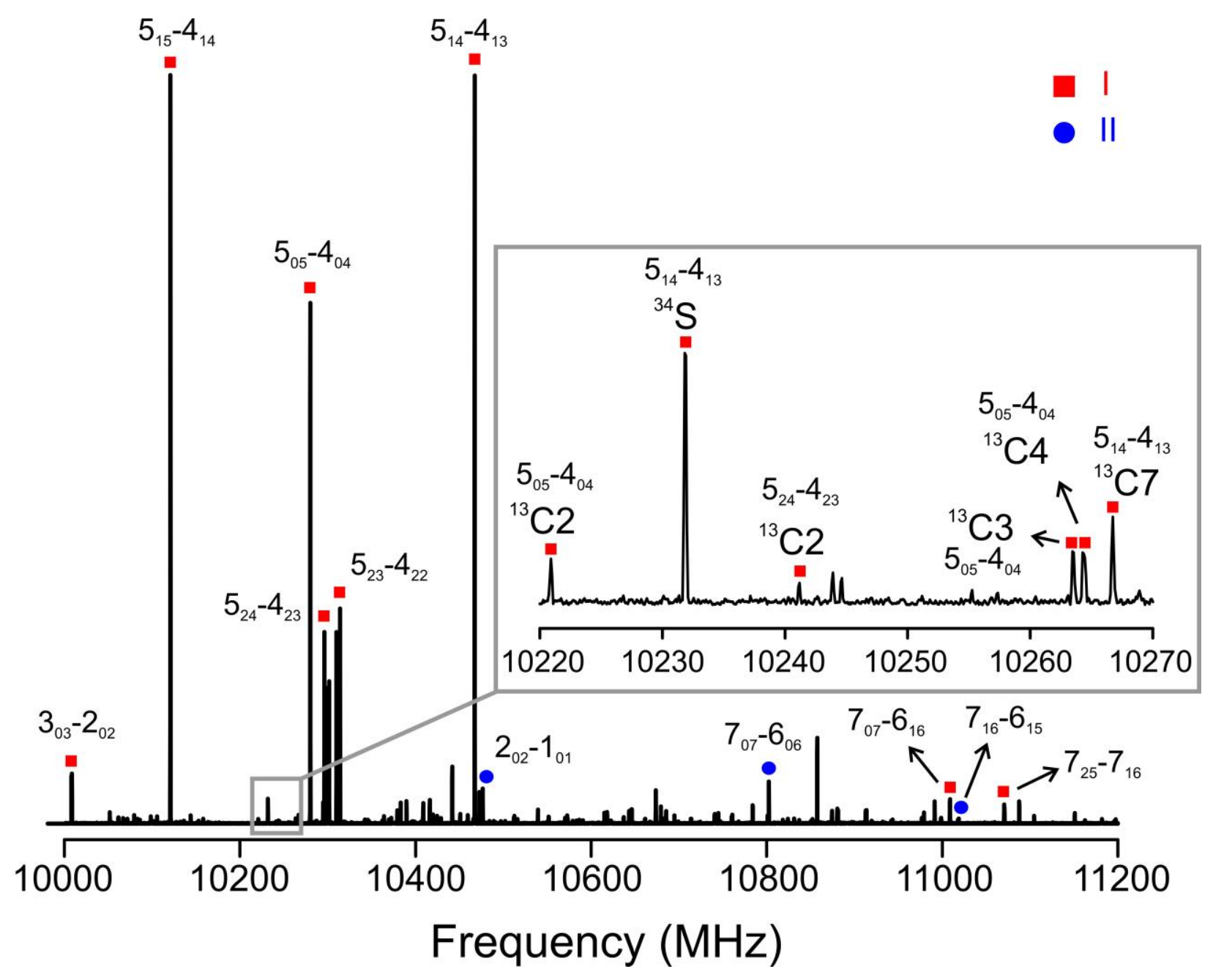

Figure 2. Portion of the broadband cp-FTMW spectrum of methyl 3-mercaptopropionate highlighting some rotational transitions observed for the species of conformers I and II. In the figure, the A-E splitting cannot be distinguished on this scale. 

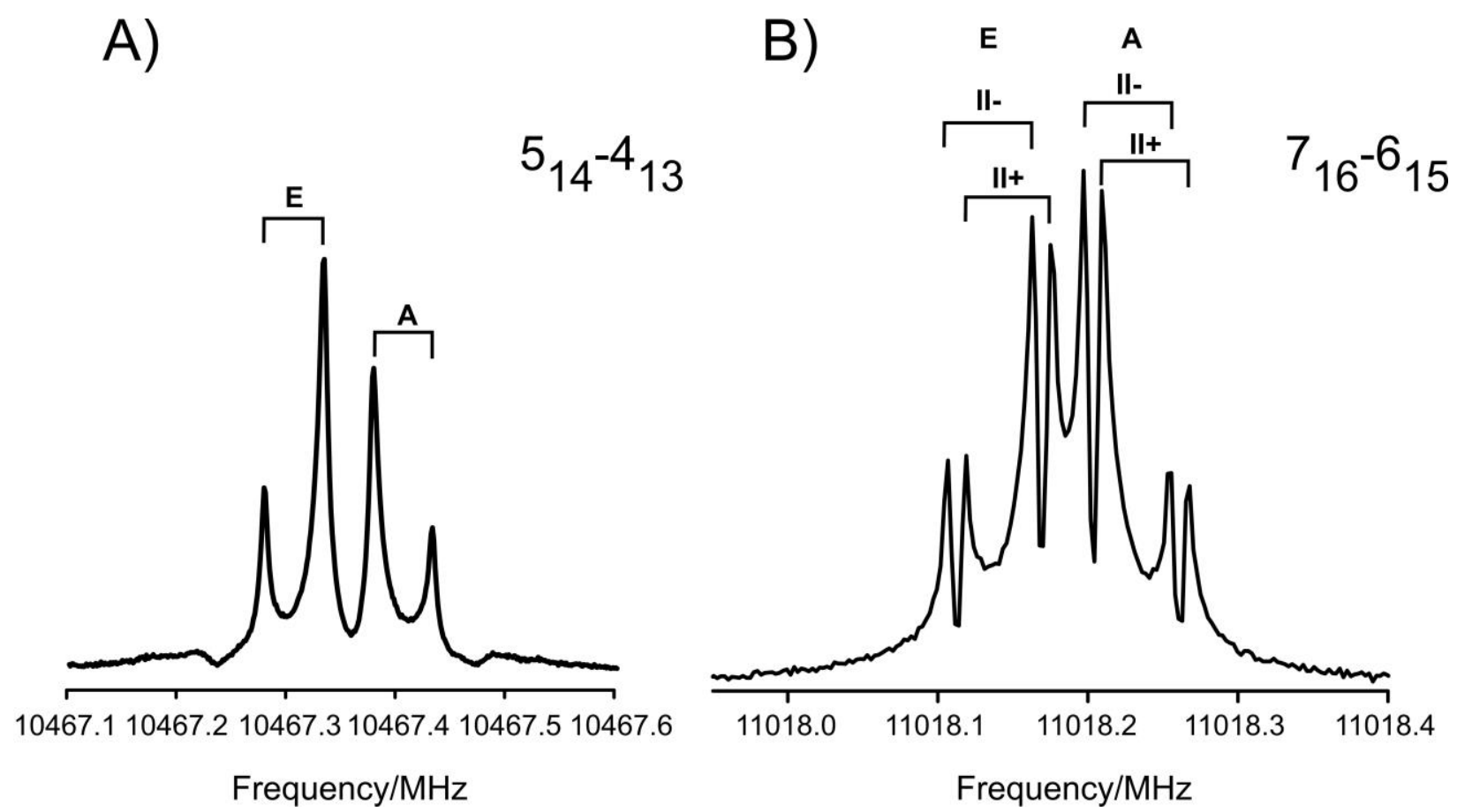

Figure 3. Sample of the cavity-based rotational spectra showing the different splitting patterns observed for the parent species of conformers A) I and B) II. The splitting is due to the internal rotation of the methyl top (A/E) and the torsion motion of the SH group (+/-).

The experimental transition frequencies for the parent and isotopic species of $\mathbf{I}$ were fit using the XIAM program ${ }^{32}$ which applies the combined axis method (CAM) to account for the methyl internal rotation. The program is suitable for relatively high barrier cases such as the ones experienced here. For II, on the other hand, due to the presence of the additional splitting, two different approaches were used to test which would provide a better model. First, separate XIAM fits were performed for each of the two tunnelling states associated with the torsion of the SH group, labeled by us as II+ and II-. This approach has also been used in the study of monohydrate complexes containing similar internal motions. ${ }^{33,34}$ Afterwards, we were also able to fit the A and E states independently using Pickett's SPFIT program. ${ }^{35}$ Since the structures of both conformers are that of near prolate asymmetric tops, Watson's S-reduced Hamiltonian ${ }^{36}$ in the $\mathrm{I}^{\mathrm{r}}$ representation 
was used for all performed fits. The experimental rotational, centrifugal distortion, and internal rotation constants for species I and II are shown in Tables 2 and 3, respectively. The full lists of measured rotational transitions, assignments and residuals for the least squares fits are given in Tables S10-S19 of the SI. 
Table 2. Experimental spectroscopic parameters for the species of conformer I of 3MP. Watson's S-reduced Hamiltonian ( ${ }^{\mathrm{r}}$ representation).

\begin{tabular}{|c|c|c|c|c|c|c|c|}
\hline & Parent & ${ }^{34} \mathrm{~S}$ & ${ }^{13} \mathrm{C} 2$ & ${ }^{13} \mathrm{C} 3$ & ${ }^{13} \mathrm{C} 4$ & ${ }^{13} \mathrm{C} 7$ & B3LYP-D3BJ \\
\hline$A(\mathrm{MHz})$ & $5067.02148(76)$ & $5026.1976(21)$ & $5020.1700(33)$ & $4992.109(40)$ & $5063.684(51)$ & $5049.805(66)$ & 5046 \\
\hline$B(\mathrm{MHz})$ & $1064.48640(79)$ & $1040.28494(17)$ & $1058.63732(41)$ & $1064.47025(18)$ & $1062.77678(21)$ & $1043.83172(19)$ & 1055 \\
\hline$C(\mathrm{MHz})$ & $995.13673(89)$ & $973.43053(18)$ & $989.18841(39)$ & $992.21527(17)$ & $993.67461(23)$ & $976.74003(22)$ & 987 \\
\hline$D_{\mathrm{J}}(\mathrm{kHz})$ & $0.40681(50)$ & $0.39954(66)$ & $0.3987(13)$ & $0.40117(56)$ & $0.40595(67)$ & $0.39227(69)$ & 0.39 \\
\hline$D_{\mathrm{JK}}(\mathrm{kHz})$ & $-6.1099(29)$ & $-6.1497(71)$ & $-5.895(14)$ & $-5.9614(65)$ & $-6.1109(74)$ & $-6.0213(85)$ & -6.00 \\
\hline$D_{\mathrm{K}}(\mathrm{kHz})$ & $43.65(15)$ & $44.27(37)$ & {$[43.65]$} & {$[43.65]$} & [43.65] & [43.65] & 45.17 \\
\hline$d_{1}(\mathrm{kHz})$ & $0.01276(53)$ & $0.01050(75)$ & $0.0106(19)$ & $0.01026(87)$ & $0.0136(10)$ & $0.0124(11)$ & 0.01 \\
\hline$d_{2}(\mathrm{kHz})$ & $-0.00359(28)$ & $-0.00231(46)$ & {$[-0.00359]$} & {$[-0.00359]$} & {$[-0.00359]$} & {$[-0.00359]$} & -0.003 \\
\hline$V_{3}(\mathrm{~kJ} / \mathrm{mol})$ & $5.0696(87)$ & $5.0696(13)$ & $5.0858(47)$ & $5.0782(18)$ & $5.0821(21)$ & $5.0887(21)$ & \\
\hline$F_{0}(\mathrm{GHz})$ & $161.12(26)$ & {$[161.12]$} & [161.12] & [161.12] & {$[161.12]$} & [161.12] & \\
\hline$\delta(\mathrm{rad})$ & $0.6330(13)$ & $0.6376(16)$ & $0.6115(55)$ & $0.6210(21)$ & $0.6234(24)$ & $0.6123(24)$ & \\
\hline$I_{\alpha}\left(\mathrm{u}^{2}\right)$ & $3.1365(50)$ & [3.1365] & {$[3.1365]$} & [3.1365] & [3.1365] & [3.1365] & \\
\hline$N^{\mathrm{a}}$ & 117 & 101 & 53 & 51 & 47 & 41 & \\
\hline$\sigma^{\mathrm{b}}(\mathrm{kHz})$ & 2.2 & 3.0 & 3.5 & 1.5 & 1.6 & 1.4 & \\
\hline
\end{tabular}

${ }^{[a]}$ Number of lines in the fit; ${ }^{[b]}$ Root-mean-square deviation of the fit. Values in [] were fixed to the calculated values.

Table 3. Experimental spectroscopic parameter for the parent species of conformer II of 3MP. Watson's S-reduced Hamiltonian $\left(I^{\mathrm{r}}\right.$ representation).

\begin{tabular}{|c|c|c|c|c|c|}
\hline & \multicolumn{2}{|c|}{ XIAM } & \multicolumn{2}{|c|}{ SPFIT } & \multirow[t]{2}{*}{ B3LYP-D3BJ } \\
\hline & $\mathrm{II}+(\mathrm{A}+/ \mathrm{E}+)$ & II- (A-/E-) & $\mathrm{A}+/ \mathrm{A}-$ & $\mathrm{E}+/ \mathrm{E}-$ & \\
\hline$A(\mathrm{MHz})$ & $8242.8876(34)$ & $8242.8885(43)$ & $8244.1907(20)$ & $8242.2278(57)$ & 8256 \\
\hline$B(\mathrm{MHz})$ & $801.74647(17)$ & 801.74804(19) & $801.74070(21)$ & $801.73912(23)$ & 796 \\
\hline$C(\mathrm{MHz})$ & 744.12096(16) & 744.12031(19) & $744.12821(20)$ & $744.12826(27)$ & 739 \\
\hline$D_{\mathrm{J}}(\mathrm{kHz})$ & $0.02566(73)$ & $0.02556(86)$ & $0.02659(98)$ & $0.0250(11)$ & 0.02 \\
\hline$D_{\mathrm{JK}}(\mathrm{kHz})$ & {$[0.21]$} & {$[0.21]$} & {$[0.21]$} & {$[0.21]$} & 0.21 \\
\hline$D_{\mathrm{K}}(\mathrm{kHz})$ & [13.49] & [13.49] & [13.49] & [13.49] & 13.49 \\
\hline$d_{1}(\mathrm{kHz})$ & {$[-0.002]$} & {$[-0.002]$} & {$[-0.002]$} & {$[-0.002]$} & -0.002 \\
\hline$d_{2}(\mathrm{kHz})$ & [0.00009] & [0.00009] & [0.00009] & [0.00009] & 0.00009 \\
\hline$V_{3}(\mathrm{~kJ} / \mathrm{mol})$ & $4.567(28)$ & $4.563(36)$ & & & \\
\hline$F_{0}(\mathrm{GHz})$ & $144.67(74)$ & 144.32(99) & & & \\
\hline$\delta(\mathrm{rad})$ & $0.236(20)$ & $0.227(24)$ & & & \\
\hline $\mathrm{Da}(\mathrm{MHz})$ & & & & $19.271(17)$ & \\
\hline$I_{\alpha}\left(\mathrm{u} \AA^{2}\right)$ & $3.493(18)$ & $3.502(24)$ & & & \\
\hline$N^{\mathrm{a}}$ & 57 & 59 & 60 & 53 & \\
\hline$\sigma^{\mathrm{b}}(\mathrm{kHz})$ & 4.8 & 5.8 & 6.4 & 6.8 & \\
\hline
\end{tabular}

${ }^{[a]}$ Number of lines in the fit; ${ }^{[b]}$ Root-mean-square deviation of the fit. Values in [] were fixed to the calculated values. 


\section{DISCUSSION}

\section{Rotational Spectroscopic Data}

The highly accurate experimentally-derived ground state rotational constants $(A, B$, and $C)$ for 3MP show good agreement with those of the equilibrium geometries obtained theoretically. This unequivocally confirms the assignment of conformers I and II. The B3LYP-D3BJ method provides the best match with the experimental data, where the largest deviation $(\sim 21 \mathrm{MHz})$ is observed for the $A$ rotational constant of the parent species of $\mathbf{I}$. The quartic centrifugal distortion constants $\left(D_{\mathrm{J}}, D_{\mathrm{JK}}, D_{\mathrm{K}}, d_{1}\right.$, and $\left.d_{2}\right)$ agree very well with the calculated ones obtained through anharmonic frequency calculations at the B3LYP-D3BJ/aug-cc-pVTZ level of theory, providing an additional check for the assignments. The B3LYP-D3BJ method also showed the best results

for the carboxylic acid version of 3MP, 3-mercaptopropionic acid. ${ }^{10}$ The experimental three-fold barrier to internal rotation $V_{3}$, along with other internal rotor parameters, such as the rotational constant of the methyl top $\left(F_{0}\right)$, the angle between its $\alpha$-axis and the principal $a$-axis of the molecule $(\delta)$, and its moment of inertia $\left(I_{\alpha}\right)$, were successfully obtained with the XIAM code.

The parameters that were not well-determined in the fits were fixed to either the parent species values, as in the case of some centrifugal distortion and internal rotation constants for the singly substituted isotopes of $\mathbf{I}$, or the calculated ones, as for some centrifugal distortion constants of II. In the case of the latter, we also performed both the XIAM and SPFIT fits by varying only

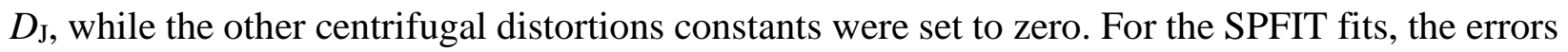
in the fits were similar to the ones reported in Table $3\left(\sigma=6.4 \mathrm{kHz}\right.$ for $\mathrm{A}^{+} / \mathrm{A}^{-}$, and $\sigma=6.3 \mathrm{kHz}$ for $\mathrm{E}^{+} / \mathrm{E}^{-}$), while for the XIAM fits the values of $\sigma$ were $2.8 \mathrm{kHz}$ and $7.0 \mathrm{kHz}$ for II+ and II-, respectively. With the constants fixed, satisfactory fits were obtained, which confirms that isotopic 
substitution does not significantly change the parameter values, and that the employed level of theory describes the system under investigation well.

For conformer II, it is worth noting that the absence of cross-tunneling $c$-type rotational transitions in our spectrum prevented us from determining the energy difference between the A+/A- or E+/E- in the conformer II states in the SPFIT fits but the A and E states were fit independently. This fitting approach is typical for molecular systems having both an internal $V_{3}$ rotor and a separate tunnelling motion that involves the torsion of a water subunit in a complex, as specified previously in ref. 33 and 34 . However, when the second tunneling involves $\sim 120^{\circ}$ rotation of a hydroxyl $(-\mathrm{OH})$ or even bigger group, ${ }^{37}$ the fits for the + and - states are coupled. Interestingly, this might be one of the first cases where a system containing tunneling splitting from both internal $V_{3}$ rotation and another torsional motion provide reasonable independent fits without the consideration of Coriolis coupling effects. For example, in the rotational spectroscopic study of the formic-acetic acid complex, ${ }^{38}$ which presents complex splitting patterns due to coupled internal motions from methyl internal rotation and double proton transfer, the authors mention that they were not able to treat the A and E states independently, since the fits for the E state were not satisfactory without the inclusion of transitions that connect the tunneling states.

\section{Tunneling Motions}

The potential energy surface for the internal rotation of a methyl group possess three equivalent energy minima and gives rise to a non-degenerate (A) and twofold degenerate (E) state which result in rotational transitions that are tunneling split. Figure 4 shows the theoretical potentials for the rotation of the methyl group in conformers I and II where both B3LYP-D3BJ and MP2 methods predict the two geometries to have similar barriers to internal rotation of 
approximately $3.6 \mathrm{~kJ} \mathrm{~mol}^{-1}$ and $4.8 \mathrm{~kJ} \mathrm{~mol}^{-1}$, respectively. The experimentally determined threefold barriers $V_{3}$ obtained for each conformer are indeed similar and have values of about $5.1 \mathrm{~kJ}$ $\mathrm{mol}^{-1}$ and $4.6 \mathrm{~kJ} \mathrm{~mol}^{-1}$ for $\mathbf{I}$ and II, respectively. Although it has been shown that conformational changes can lead to significant variations in $V_{3}$, as shown in the rotational study of thioacetic acid for example, ${ }^{11}$ the differences in the geometries of $\mathbf{I}$ and $\mathbf{I I}$ do not strongly affect the methyl internal rotation in $3 \mathrm{MP}$. Since the $V_{3}$ barriers depend on steric hindrance and the electronic structure of molecules, ${ }^{11,14}$ the experimental outcomes in this work suggest that the electronic distribution of the methyl groups in $\mathbf{I}$ and $\mathbf{I I}$ are very similar. Thus, even though $\mathbf{I}$ is expected to be stabilized by an $\mathrm{SH}^{\cdots} \mathrm{O}=\mathrm{C}$ intramolecular hydrogen bond (IHB), this interaction does not seem to play an important role in the rotation of the methyl top. The experimental $V_{3}$ barriers obtained for the 3MP conformers are also similar to values reported in the literature for its smaller version (methyl thioglycolate, $\left.V_{3} \sim 4.9 \mathrm{~kJ} \mathrm{~mol}^{-1}\right)^{39}$ and other studied systems containing esters as functional groups, such as its hydrocarbon version: methyl propionate $\left(V_{3} \sim 5.1 \mathrm{~kJ} \mathrm{~mol}^{-1}\right) .^{40} \mathrm{By}$ comparing the results, one can see that changes in the side chain of the molecule with respect to the ester group in those examples, such as the presence of a five-membered ring in the former, and the absence of the SH group in the latter, do not lead to significant variations in the internal of rotation of the methyl top. 
A)
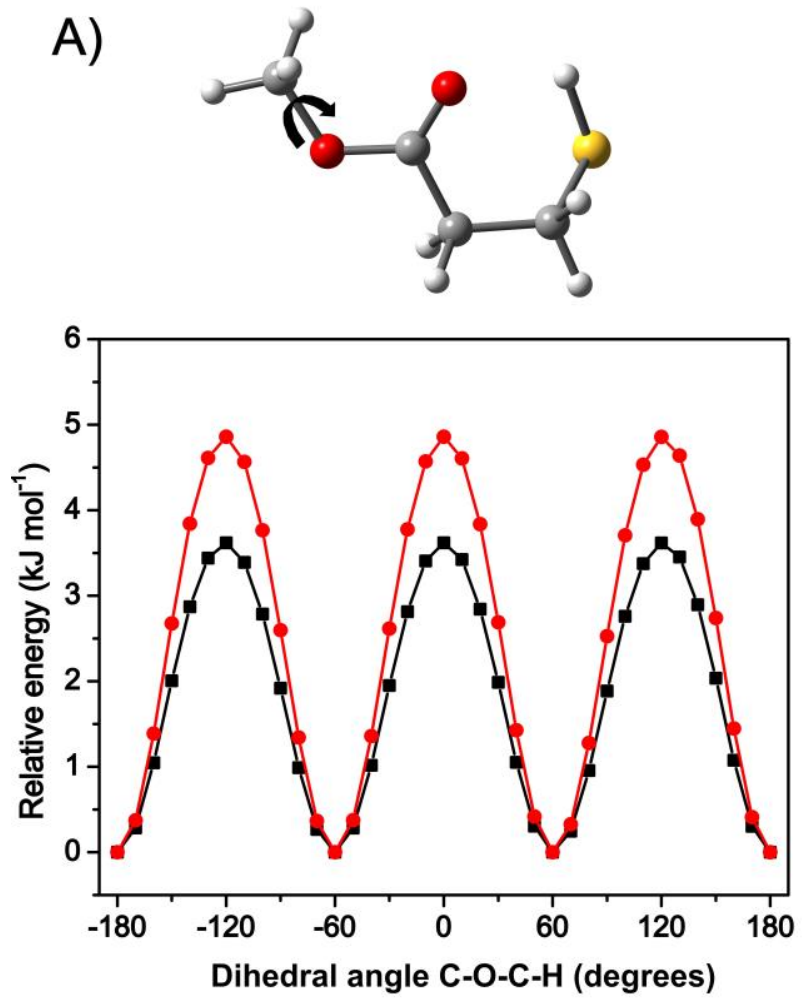

- B3LYP-D3BJ
B)
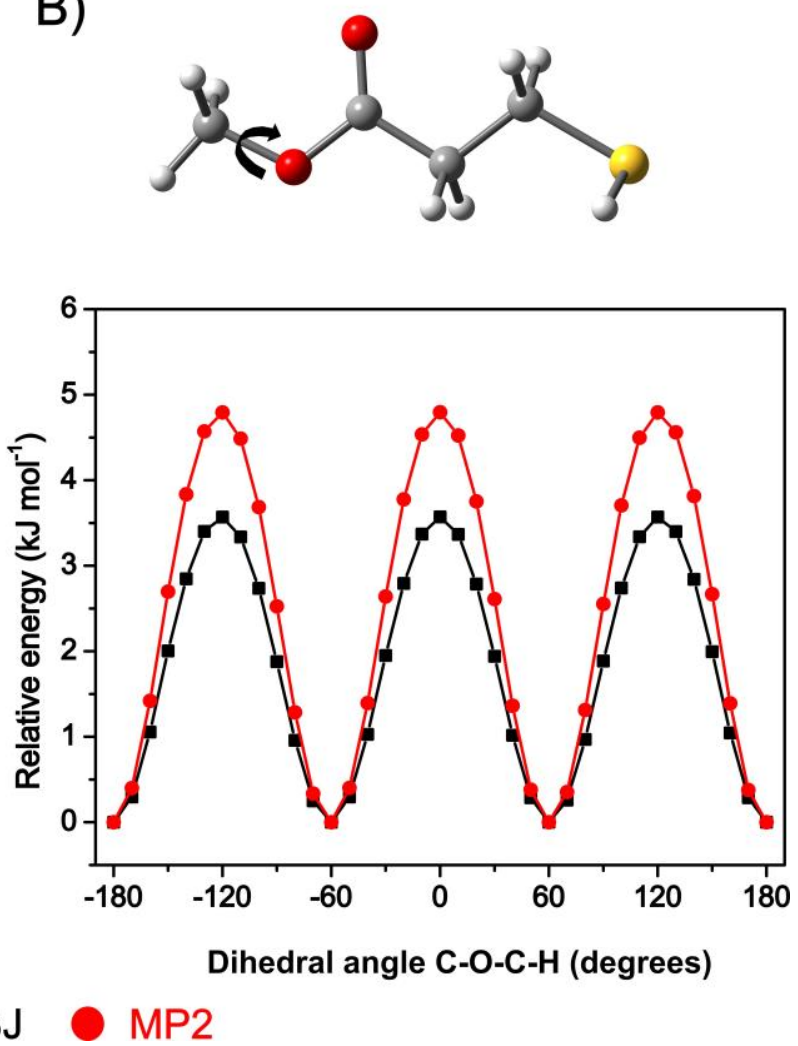

Figure 4. Potential energy curves for the methyl internal rotation in conformers A) I and B) II. The plots were obtained using the B3LYP-D3BJ and MP2 methods with the aug-cc-pVTZ basis set by varying the $\mathrm{C}-\mathrm{O}-\mathrm{C}-\mathrm{H}$ dihedral angle in 36 steps of 10 degrees each.

To better understand the additional tunneling splitting observed in the rotational transitions of II, attributed to a torsional motion of the SH group, we performed scan calculations by rotating the C-C-S-H dihedral angle in 36 steps of 10 degrees each. This shows that the observed tunneling is characterized by a double-well potential energy function (Figure 5) that allows the interconversion between the two equivalent forms (mirror images) of II through a calculated energy barrier of approximately $7.0 \mathrm{~kJ} \mathrm{~mol}^{-1}$. The predicted barriers are consistent with the small splitting observed experimentally. 


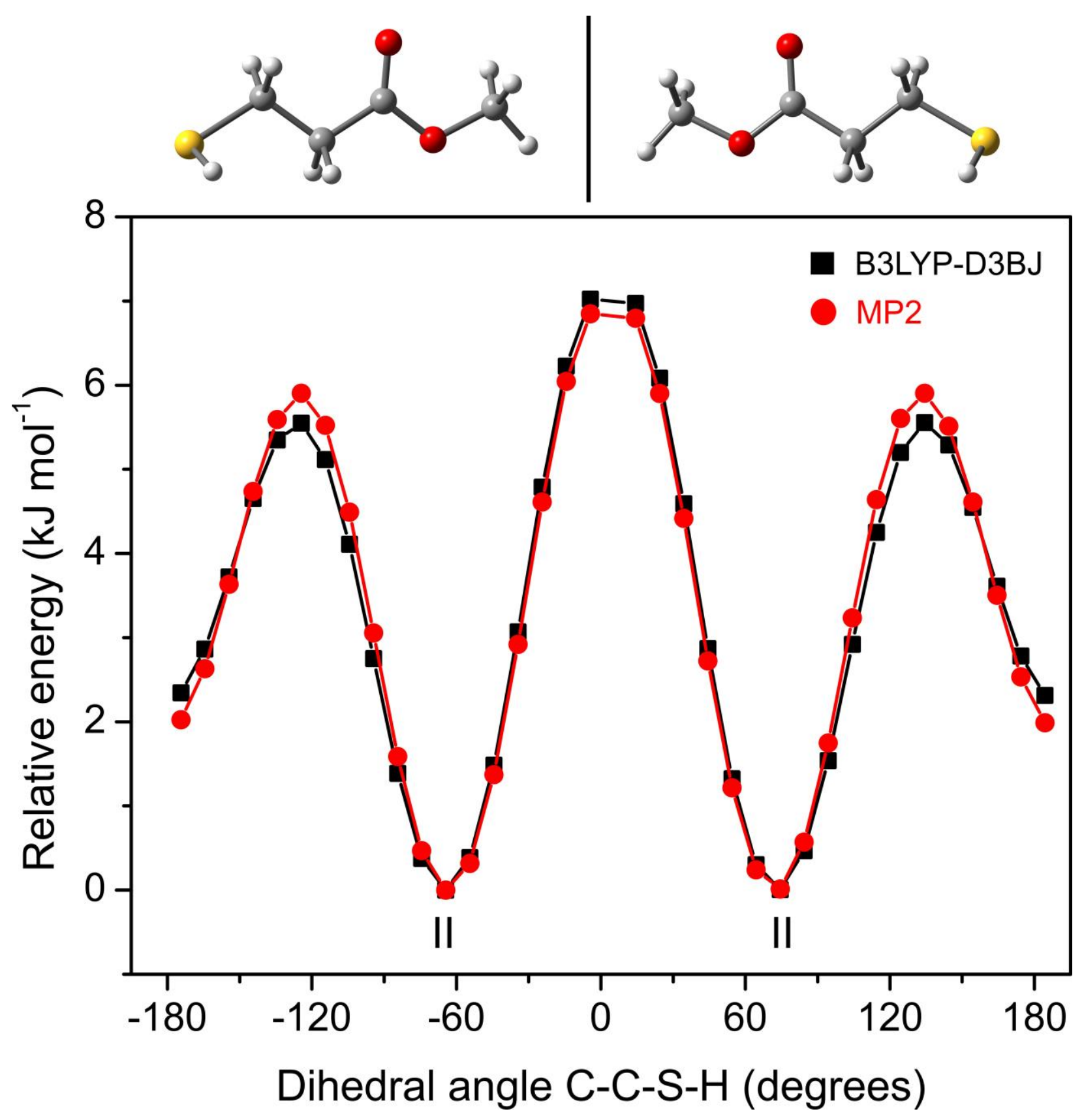

Figure 5. Potential energy curve for the torsional motion of the SH group in conformer II. The plot was obtained by the rotation of the SH group around the C-S bond in 36 steps of 10 degrees each using the B3LYP-D3BJ and MP2 methods with the aug-cc-pVTZ basis set. 


\section{Relaxation Pathways}

Despite an extensive experimental search, transitions due to other conformers were not identified in the rotational spectrum of 3MP. The experimentally observed conformers I and II are predicted to account for more than $58.7 \%$ (Table 1) of the total conformational equilibrium $(100.0 \%)$ at room temperature, while the remaining population is spread among the other true energy minima. Since we were able to detect transitions belonging to the ${ }^{13} \mathrm{C}$ singly substituted isotopes of I which are about 1.0\% of the intensity observed for the parent species, one may expect the observation of other higher energy conformations in the supersonic jet, such as conformer III (Table 1).

To explore the absence of transitions related to additional geometries in the rotational spectra, we carefully investigated the complex conformational distribution and predicted relaxation pathways for the conversion of higher energy conformations to lower energetic ones. It is well known from empirical studies that in the supersonic jet expansion, energy barriers of rearrangements of $\sim 4.8 \mathrm{~kJ} \mathrm{~mol}^{-1}$ or higher prevent relaxation and allow the observation of metastable conformers. ${ }^{41}$ For example, the only difference in the geometries of $\mathbf{I I}$ and $\mathbf{V}$ is in the orientation of the SH group and thus, relaxation from $\mathbf{V}$ to II could take place in the supersonic jet depending on the energy required for this $\mathrm{SH}$ torsional motion. The conversion pathway from $\mathbf{V}$ to II, calculated by the rotation of the SH group in 24 steps of 10 degrees each (Figure 6A), reveals an energy barrier of approximately $3.2 \mathrm{~kJ} \mathrm{~mol}^{-1}-3.9 \mathrm{~kJ} \mathrm{~mol}^{-1}$. Thus, $\mathbf{V}$ is expected to experience facile relaxation in the supersonic jet and will not be observed experimentally. Likewise, we carried out several scan calculations for possible relaxation pathways between other similar conformer pairs and the obtained potential energy curves are shown in Figures S1 of the ESI. The calculations indicate that the following relaxations may occur during the experiments: $\mathbf{V} \rightarrow \mathbf{I I}(3.2$ 
$\left.\mathrm{kJ} \mathrm{mol}{ }^{-1}-3.9 \mathrm{~kJ} \mathrm{~mol}^{-1}\right), \mathbf{V I} \rightarrow \mathbf{I}\left(0.0 \mathrm{~kJ} \mathrm{~mol}^{-1}-0.3 \mathrm{~kJ} \mathrm{~mol}^{-1}\right), \mathbf{V I I I} \rightarrow \mathbf{I}\left(2.3 \mathrm{~kJ} \mathrm{~mol}^{-1}-2.9 \mathrm{~kJ} \mathrm{~mol}^{-1}\right)$, and IX $\rightarrow$ VIII $\left(1.1 \mathrm{~kJ} \mathrm{~mol}^{-1}-1.6 \mathrm{~kJ} \mathrm{~mol}^{-1}\right)$. Therefore, conformers $\mathbf{V}, \mathbf{V I}$, VIII, and IX are not expected to be observed experimentally.

A)

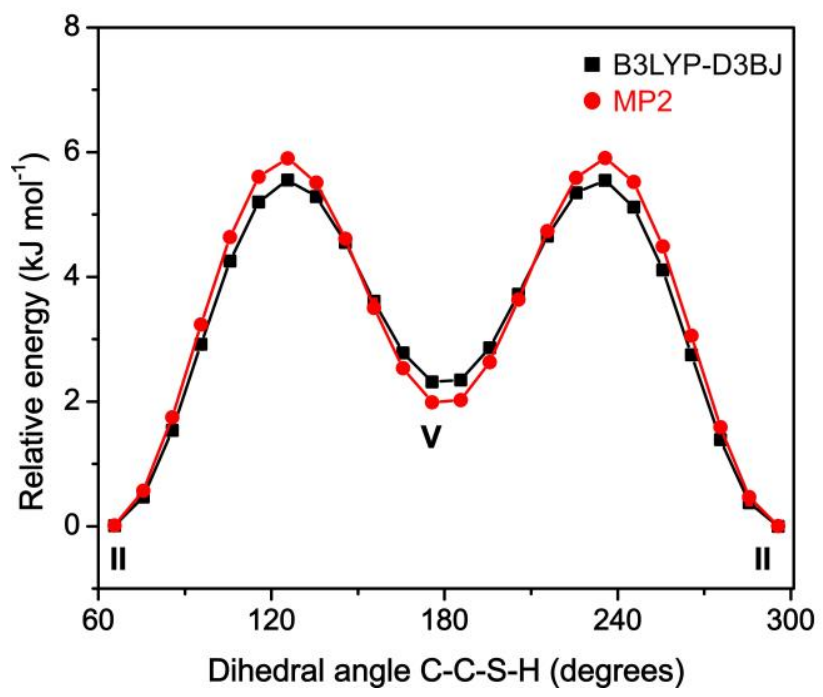

B)

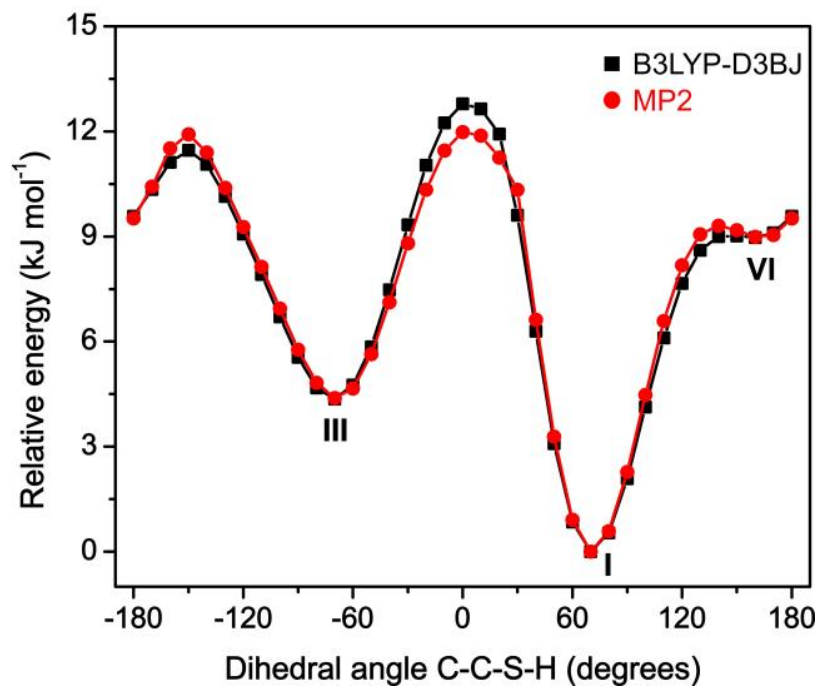

Figure 6. Conversion pathway between conformers A) II and V and B) III, I, and VI obtained by varying the torsional motion of the $\mathrm{SH}$ group. The potential energy curves were calculated using the B3LYP-D3BJ and MP2 methods with the aug-cc-pVTZ basis set.

Theoretically, the barrier of conversion (approximately $8.4 \mathrm{~kJ} \mathrm{~mol}^{-1}-7.6 \mathrm{~kJ} \mathrm{~mol}^{-1}$ ) from III to I (Figure 6B) would prevent its relaxation in the supersonic jet and III should be observed experimentally. It is worth noting that the conversion $\mathbf{V I} \rightarrow \mathbf{I}$, which also involves the SH torsion motion, is estimated to be barrier-less while that calculated from $\mathbf{I I I} \rightarrow \mathbf{I}$ is relatively high. The main reason for the high energy barrier in the latter is because in the conversion pathway from III to I, the transition state structure adopts a geometry where the SH group is oriented towards the non-carbonyl oxygen of the ester $\left(\mathrm{C}-\mathrm{C}-\mathrm{S}-\mathrm{H} \approx 0^{\circ}\right)$ which likely increases the energy of conversion. Although III should be metastable in the supersonic jet, its spectrum is dominated by $c$-type 
transitions and as only a few fall within the range of our spectrometer, a convincing assignment for conformer III was not attained.

\section{Intramolecular Hydrogen Bond and Structural Determination Analysis}

To confirm the stability and to estimate the strength of the $\mathrm{S}-\mathrm{H} \cdots \mathrm{O}=\mathrm{C}$ intramolecular hydrogen bond (IHB) in conformer $\mathbf{I}$, we carried out quantum theory of atoms in molecules (QTAIM) and non-covalent interactions (NCI) analyses. The NCI analysis (Figure 7A) shows a weak attractive (blue-greenish isosurface) interaction for the $\mathrm{S}-\mathrm{H} \cdots \mathrm{O}=\mathrm{C}$ close contact. The interaction is confirmed by the QTAIM analysis (Figure 7B) where a bond path (BP) and a bond critical point $(\mathrm{BCP})$ are visualized between the thiol hydrogen and the carbonyl oxygen. The QTAIM molecular graph also shows a ring critical point (RCP) related to the repulsive interactions of the six-membered ring which arises upon $\mathrm{HB}$ formation. The energy of the $\mathrm{S}-\mathrm{H} \cdots \mathrm{O}=\mathrm{C}$ IHB can be estimated using the electronic potential energy at the $\mathrm{BCP}\left(V_{\mathrm{BCP}}\right)$, as $E_{\mathrm{IHB}}=0.5\left|V_{\mathrm{BCP}}\right| .^{42}$ The calculated $E_{\mathrm{IHB}}$ in $\mathbf{I}$ is of about $6.6 \mathrm{~kJ} \mathrm{~mol}^{-1}$ which confirms the weak character of the $\mathrm{S}-\mathrm{H} \cdots \mathrm{O}=\mathrm{C}$ IHB. In addition to the QTAIM and NCI topological analyses, we also carried out the natural bond orbital (NBO) calculations at the B3LYP-D3BJ/aug-cc-pVTZ level of theory. The NBO results show charge transfer from both lone-pairs $\left[\mathrm{LP}_{1}(\mathrm{O})\right.$ and $\left.\mathrm{LP}_{2}(\mathrm{O})\right]$ of the carbonyl oxygen to the antibonding orbital of the S-H bond $\left(\sigma^{*}\right.$ S-H $)$, evidenced by $\mathrm{LP}_{1}(\mathrm{O}) \rightarrow \sigma^{*}{ }_{\mathrm{S}-\mathrm{H}}=0.3 \mathrm{~kJ} \mathrm{~mol}^{-1}$ and $\mathrm{LP}_{2}(\mathrm{O})$ $\rightarrow \sigma^{*}{ }_{\mathrm{S}-\mathrm{H}}=1.4 \mathrm{~kJ} \mathrm{~mol}^{-1}$ hyperconjugative interactions, which also confirms the occurrence of the weak $\mathrm{S}-\mathrm{H}^{\cdots} \mathrm{O}=\mathrm{C}$ IHB in $\mathbf{I}$. Overall, the three computational approaches suggest that the presence of the sulfur IHB in $\mathbf{I}$ is the main reason for its higher stability over the other conformers. The role of this interaction has also been shown to be the explanation for the stabilization of the global minimum geometry of its acid analog. ${ }^{10}$ 
A)

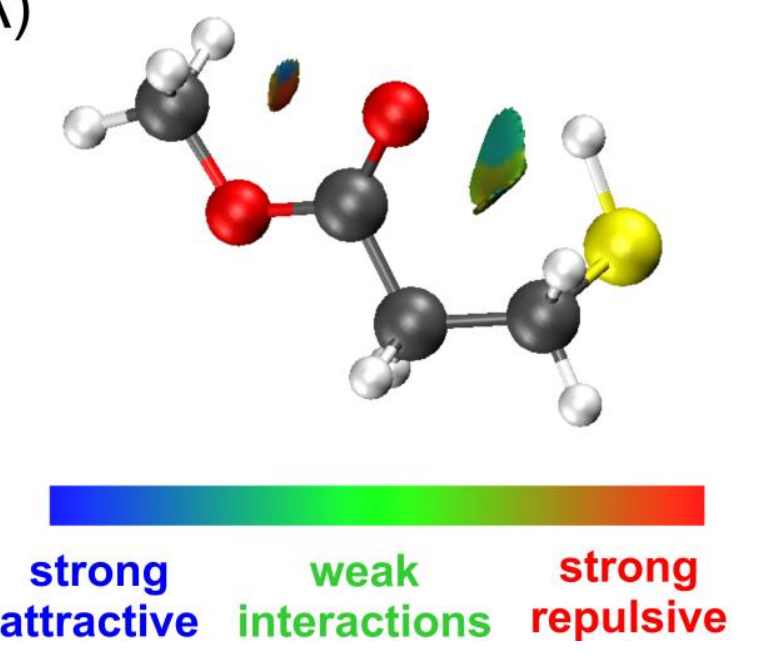

B)

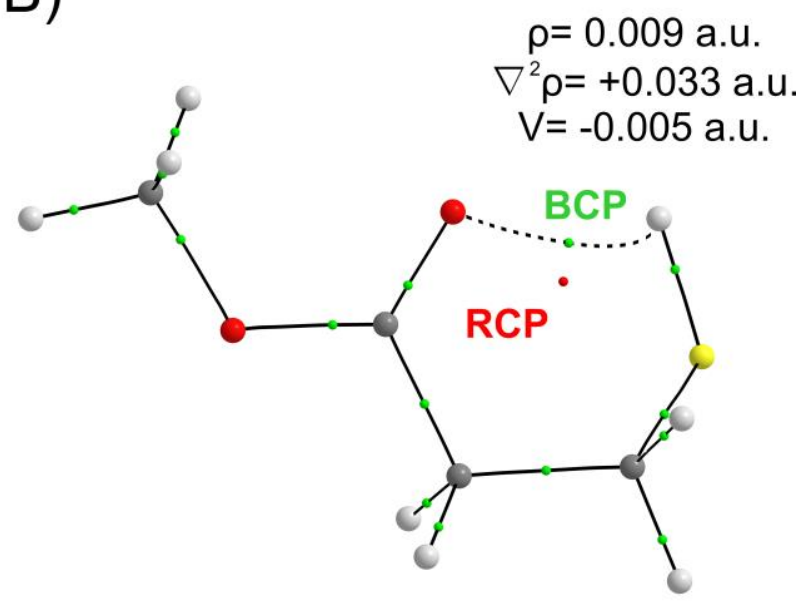

Figure 7. A) NCI isosurface ( $s=0.5 \mathrm{au}$; colour scale of $-0.02<\rho<0.02)$ and B) QTAIM molecular graph of conformer I. $\rho, \nabla^{2} \rho$, and $\mathrm{V}$ are the electron density, its Laplacian, and the potential energy at the $\mathrm{BCP} \mathrm{S}-\mathrm{H}^{\cdots} \mathrm{O}=\mathrm{C}$.

Based on the experimental determination of the rotational constants for the parent species of $\mathbf{I}$ and its minor ${ }^{34} \mathrm{~S}$ and ${ }^{13} \mathrm{C}$ singly substituted isotopic species, we derive key geometric parameters from its partial ground state geometry $r_{0}$ using Kisiel's STRFIT ${ }^{43}$ least squares fitting program. Since our interest lies in understanding the $\mathrm{IHB} \mathrm{SH}^{\cdots} \mathrm{O}=\mathrm{C}$, we focused our structural determination on the bond lengths and angles associated with the six-membered ring formed due to the IHB. The set of 18 rotational constants were used to fit six parameters which are the S1-C2, $\mathrm{C} 2-\mathrm{C} 3$, and $\mathrm{C} 3-\mathrm{C} 4$ bond distances, $\mathrm{S} 1-\mathrm{C} 2-\mathrm{C} 3$ and $\mathrm{C} 2-\mathrm{C} 3-\mathrm{C} 4$ bond angles, and the S1-C2-C3-C4 dihedral angle, while the other distances and angles were fixed to the values from B3LYP-D3BJ/aug-cc-pVTZ. By using the principal coordinates and their estimated uncertainties from the STRFIT outcome, the HB distance O5 $\cdots \mathrm{H} 8$ and angles C4-O5-H8 and S1-H8-O5, and the distance of the $\mathrm{S} 1-\mathrm{H} 8$ and $\mathrm{C} 4=\mathrm{O} 5$ bonds were determined trigonometrically along with their propagated uncertainties using the EVAL program. ${ }^{44}$ The values for the fit parameters and their associated uncertainties along with the equilibrium geometries obtained theoretically are shown in 
Table 4. The derived parameters confirm the gauche arrangement of the backbone where the dihedral angle S1-C2-C3-C4 is equal to $-68.9(2)^{\circ}$ and reveal that the HB distance H8 $\cdots$ O5 and angle S1-H8-O5 are 2.515(4) $\AA$ and $117.4(1)^{\circ}$, respectively. The H8 ${ }^{\cdots} \mathrm{O} 5$ is less than the sum of their van der Waals radii $(\sim 2.72 \AA)$, and the angle $\mathrm{S} 1-\mathrm{H} 8-\mathrm{O} 5$ is consistent with the ones observed for six-membered ring HBs. The HB distance involving the carbonyl oxygen in I is slightly smaller when compared to the intermolecular $\mathrm{SH}^{\cdots} \mathrm{O} \mathrm{HB}$ distance of $2.44(3) \AA$ observed in the monohydrated cluster of furfuryl mercaptan. ${ }^{8}$ By comparing the hydrogen bond parameters obtained for the $\mathrm{S}-\mathrm{H}^{\cdots} \mathrm{O}=\mathrm{C}$ in $3 \mathrm{MP}$ with the ones of the six-membered ring $\mathrm{O}-\mathrm{H} \cdots \mathrm{O}=\mathrm{C}$ in 3-hydroxypropionic acid, ${ }^{45}$ once can see that the $\mathrm{HB}$ distance $\mathrm{S}-\mathrm{H} \cdots \mathrm{O}[2.515(4) \AA]$ in the former is slightly longer when compared to the $\mathrm{O}-\mathrm{H}^{\cdots} \mathrm{O}(2.127 \AA)$ in the latter. On the other hand, the angle S-H-O $\left[117.4(1)^{\circ}\right]$ is slightly smaller than the O-H-O $\left(129.6^{\circ}\right)$. The observed differences in the HB distances and angles are consistent with the fact that the oxygen analog is expected to present stronger $\mathrm{HBs}$ when compared to the sulfur one. Although weaker than the $\mathrm{O}-\mathrm{H} \cdots \mathrm{O}=\mathrm{C}$, the experimental results in this work clearly shows the importance of the $\mathrm{S}-\mathrm{H} \cdots \mathrm{O}=\mathrm{C}$ IHB in ruling the conformational equilibrium of S-containing compounds, in particular, 3MP. 
Table 4. Ground state effective $\left(r_{0}\right)$ and equilibrium $\left(r_{\mathrm{e}}\right)$ (B3LYP-D3BJ/aug-cc-pVTZ) structural parameters determined for conformer I. Bond distances and angles are reported in angstroms $(\AA)$ and degrees, respectively.

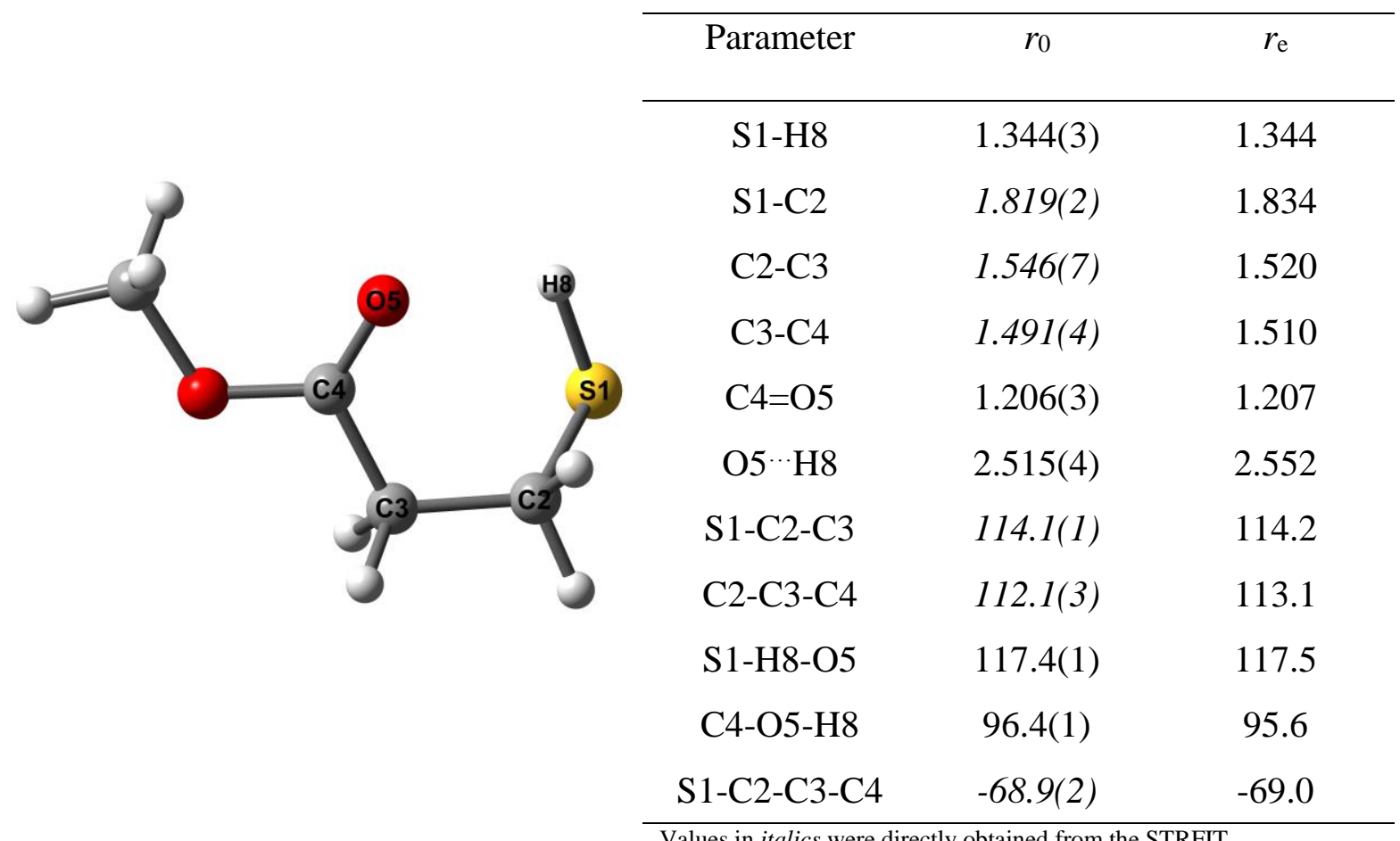




\section{Conclusions}

The ground state rotational spectrum of methyl 3-mercaptopropionate was measured and analyzed in detail using chirped-pulse and cavity-based Fourier transform microwave spectroscopy from 8-18 GHz. Rotational transitions belonging to the two most stable conformers

(I and II) were successfully assigned in the rotational spectra, and the lines present complex splitting patterns due to the methyl internal rotation and/or SH tunneling motion. The similar experimental $V_{3}$ barriers for the two conformers reveal that the electronic distribution of I and II is not strongly affected by their geometrical differences. QTAIM, NCI, and NBO analyses show that conformer I is favored in the conformational equilibrium due to a stable $\mathrm{SH} \cdots \mathrm{O}=\mathrm{C}$ IHB, which is estimated to have an energy of about $6.6 \mathrm{~kJ} \mathrm{~mol}^{-1}$ based on the potential energy at the bond critical point. On the basis of the ground state effective $\left(r_{0}\right)$ and equilibrium $\left(r_{\mathrm{e}}\right)$ geometries of $\mathbf{I}$, we were able to derive the experimental geometric parameters associated with the sulfur $\mathrm{HB}$, which reveals that the HB distance and angle S-H-O are 2.515(4) $\AA$ and $117.4(1)^{\mathrm{o}}$, respectively. The non-observation of additional conformers was rationalized based on their conversion pathways to lower energy forms and/or low population in the supersonic jet expansion. The present study provides key experimental data on sulfur HBs at the molecular level in isolation of crystal packing and solvent effects and serves as a benchmark for improved understanding and modelling of these important non-covalent interactions.

\section{Supporting Information}

Cartesian coordinates for the equilibrium structures of conformers I, II, III, IV, V, VI, VII, VIII, IX; Observed frequencies and residuals for the assigned species of conformers I and II; Relaxation pathways between conformers VII, VIII and IX, I and VIII, and VI, VII and IX. 


\section{Acknowledgements}

The authors acknowledge the Natural Sciences and Engineering Research Council of Canada (NSERC) for funding this research through the Discovery Grant program, and the University of Manitoba for its advanced research computing facility (Grex). W. G. D. P. S. is also thankful for the financial support provided by the Faculty of Graduate Studies (FGS) of the University of Manitoba through a UM Graduate Fellowship (UMGF). L.E. thanks the University of Bologna (RFO) for financial support.

\section{References}

(1) Oswald, S.; Suhm, M. A. Soft Experimental Constraints for Soft Interactions: A Spectroscopic Benchmark Data Set for Weak and Strong Hydrogen Bonds. Phys. Chem. Chem. Phys. 2019, 21, 18799-18810.

(2) Juanes, M.; Saragi, R. T.; Caminati, W.; Lesarri, A. The Hydrogen Bond and Beyond: Perspectives for Rotational Investigations of Non-Covalent Interactions. Chem. - A Eur. J. 2019, 25 (49), 11402-11411.

(3) Li, W.; Spada, L.; Tasinato, N.; Rampino, S.; Evangelisti, L.; Gualandi, A.; Cozzi, P. G.; Melandri, S.; Barone, V.; Puzzarini, C. Theory Meets Experiment for Noncovalent Complexes: The Puzzling Case of Pnicogen Interactions. Angew. Chemie Int. Ed. 2018, 57 (42), 13853-13857.

(4) Biswal H. S., Hydrogen Bonds Involving Sulfur: New Insights from ab Initio Calculations and Gas Phase Laser Spectroscopy, In Noncovalent Forces, Challenges and Advances in Computational Chemistry and Physics, $1^{\text {st }}$ Ed.; Scheiner, S., Ed.; Springer International: 
Switzerland, 2015, 2, pp. 15-45.

(5) Alkorta, I.; Rozas, I.; Elguero, J. Non-Conventional Hydrogen Bonds. Chem. Soc. Rev. 1998, 27 (2), 163.

(6) Grabowski, S. J. What Is the Covalency of Hydrogen Bonding? Chem. Rev. 2011, 111 (4), $2597-2625$.

(7) Das, A.; Mandal, P. K.; Lovas, F. J.; Medcraft, C.; Walker, N. R.; Arunan, E. The $\mathrm{H}_{2} \mathrm{~S}$ Dimer Is Hydrogen-Bonded: Direct Confirmation from Microwave Spectroscopy. Angew. Chemie Int. Ed. 2018, 57 (46), 15199-15203.

(8) Juanes, M.; Lesarri, A.; Pinacho, R.; Charro, E.; Rubio, J. E.; Enríquez, L.; Jaraíz, M. Sulfur Hydrogen Bonding in Isolated Monohydrates: Furfuryl Mercaptan versus Furfuryl Alcohol. Chem. - A Eur. J. 2018, 24 (25), 6564-6571.

(9) Mundlapati, V. R.; Ghosh, S.; Bhattacherjee, A.; Tiwari, P.; Biswal, H. S. Critical Assessment of the Strength of Hydrogen Bonds between the Sulfur Atom of Methionine/Cysteine and Backbone Amides in Proteins. J. Phys. Chem. Lett. 2015, 6 (8), $1385-1389$.

(10) Silva, W. G. D. P.; van Wijngaarden, J. Sulfur as a Hydrogen Bond Donor in the Gas Phase: Rotational Spectroscopic and Computational Study of 3-Mercaptopropionic Acid. J. Mol. Spectrosc. 2019, 362, 1-7.

(11) Smith, C. J.; Huff, A. K.; Zhang, H.; Mo, Y.; Leopold, K. R. A Strong Dependence of the $\mathrm{CH}_{3}$ Internal Rotation Barrier on Conformation in Thioacetic Acid: Microwave Measurements and an Energy Decomposition Analysis. J. Chem. Phys. 2019, 150 (13), 
134302.

(12) Eibl, K.; Stahl, W.; Kleiner, I.; Nguyen, H. V. L. Conformational Effect on the Almost Free Internal Rotation in 4-Hexyn-3-ol Studied by Microwave Spectroscopy and Quantum Chemistry. J. Chem. Phys. 2018, 149 (14), 144306.

(13) Andresen, M.; Kleiner, I.; Schwell, M.; Stahl, W.; Nguyen, H. V. L. Sensing the Molecular Structures of Hexan-2-one by Internal Rotation and Microwave Spectroscopy. ChemPhysChem 2019, 20, 2063-2073.

(14) Hakiri, R.; Derbel, N.; Nguyen, H. V. L.; Mouhib, H. Communication through the Furan Ring: The Conformational Effect on the Internal Rotation of 5-Methyl Furfural Studied by Microwave Spectroscopy. Phys. Chem. Chem. Phys. 2018, 20 (40), 25577-25582.

(15) Halgren, T. A. Merck Molecular Force Field. I. Basis, Form, Scope, Parametrizations, and Performance of MMFF94. J. Comput. Chem. 1995, 17, 490-641.

(16) Becke, A. D. Density-functional Thermochemistry. III. The Role of Exact Exchange. J. Chem. Phys. 1993, 98 (7), 5648-5652.

(17) Becke, A. D.; Johnson, E. R. A Density-Functional Model of the Dispersion Interaction. $J$. Chem. Phys. 2005, 123 (15), 154101.

(18) Grimme, S.; Ehrlich, S.; Goerigk, L. Effect of the Damping Function in Dispersion Corrected Density Functional Theory. J. Comput. Chem. 2011, 32 (7), 1456-1465.

(19) Møller, C.; Plesset, M. S. Note on an Approximation Treatment for Many-Electron Systems. Phys. Rev. 1934, 46 (7), 618-622.

(20) Dunning, T. H. Gaussian Basis Sets for Use in Correlated Molecular Calculations. I. The 
Atoms Boron through Neon and Hydrogen. J. Chem. Phys. 1989, 90 (2), 1007-1023.

(21) Frisch, M. J.; Trucks, G. W.; Schlegel, H. B.; Scuseria, G. E.; Robb, M. A.; Cheeseman, J. R.; Scalmani, G.; Barone, V.; Petersson, G. A.; Nakatsuji, H.; et al. Gaussian 16, Revision B.01; Gaussian, Inc.: Wallingford, CT, 2016.

(22) Weinhold, F.; Landis, C. R.; Glendening, E. D. What Is NBO Analysis and How Is It Useful? Int. Rev. Phys. Chem. 2016, 35 (3), 399-440.

(23) Bader, R. F. W. Atoms in Molecules. Acc. Chem. Res. 1985, 18 (1), 9-15.

(24) Johnson, E. R.; Keinan, S.; Mori Sánchez, P.; Contreras García, J.; Cohen, A. J.; Yang, W. NCI : Revealing Non-Covalent Interactions. J. Am. Chem. Soc. 2010, 132 (18), 6498-6506.

(25) Glendening, E. D.; Badenhoop, J. K.; Reed, A. E.; Carpenter, J. E.; Bohmann, J. A.; Morales, C. M.; Landis C. R.; Weinhold, F. NBO 6.0, Theoretical Chemistry Institute, University of Wisconsin: Madison, 2012.

(26) Keith, T. A. AIMAll, version 17.11.14; TK Gristmill Software: Overland Park, KS, 2016.

(27) Contreras-García, J.; Johnson, E. R.; Keinan, S.; Chaudret, R.; Piquemal, J.-P.; Beratan, D. N.; Yang, W. NCIPLOT: A Program for Plotting Noncovalent Interaction Regions. J. Chem. Theory Comput. 2011, 7 (3), 625-632.

(28) Balle, T. J.; Flygare, W. H. Fabry-Perot Cavity Pulsed Fourier Transform Microwave Spectrometer with a Pulsed Nozzle Particle Source. Rev. Sci. Instrum. 1981, 52 (1), 33-45.

(29) Evangelisti, L.; Sedo, G.; van Wijngaarden, J. Rotational Spectrum of 1,1,1-Trifluoro-2Butanone Using Chirped-Pulse Fourier Transform Microwave Spectroscopy. J. Phys. Chem. A 2011, 115 (5), 685-690. 
(30) Sedo, G.; van Wijngaarden, J. Fourier Transform Microwave Spectra of a "New" Isomer of OCS-CO2. J. Chem. Phys. 2009, 131 (4), 044303.

(31) Western, C. M. PGOPHER: A Program for Simulating Rotational, Vibrational and Electronic Spectra. J. Quant. Spectrosc. Radiat. Transf. 2017, 186, 221-242.

(32) Hartwig, H.; Dreizler, H. The Microwave Spectrum of Trans-2,3-Dimethyloxirane in Torsional Excited States. Zeitschrift für Naturforsch. A 1996, 51 (8), 923-932.

(33) Gall, J. T. A.; Thomas, J.; Xie, F.; Wang, Z.; Jäger, W.; Xu, Y. Rotational Spectroscopy of the Methyl Glycidate-Water Complex: Conformation and Water and Methyl Rotor Tunnelling Motions. Phys. Chem. Chem. Phys. 2017, 19 (43), 29508-29515.

(34) Schnitzler, E. G.; Seifert, N. A.; Ghosh, S.; Thomas, J.; Xu, Y.; Jäger, W. Hydration of the Simplest $\alpha$-Keto Acid: A Rotational Spectroscopic and Ab Initio Study of the Pyruvic AcidWater Complex. Phys. Chem. Chem. Phys. 2017, 19 (6), 4440-4446.

(35) Pickett, H. M. The Fitting and Prediction of Vibration-Rotation Spectra with Spin Interactions. J. Mol. Spectrosc. 1991, 148 (2), 371-377.

(36) Watson, J. K. G. In Vibrational Spectra and Structure a Series of Advances; Durig, J. R.; Ed.; Elsevier: New York, 1977, Vol. 6, pp. 1-89.

(37) Evangelisti, L.; Caminati, W. Internal Dynamics in Complexes of Water with Organic Molecules. Details of the Internal Motions in Tert-Butylalcohol-Water. Phys. Chem. Chem. Phys. 2010, 12 (43), 14433.

(38) Tayler, M. C. D.; Ouyang, B.; Howard, B. J. Unraveling the Spectroscopy of Coupled Intramolecular Tunneling Modes: A Study of Double Proton Transfer in the Formic-Acetic 
Acid Complex. J. Chem. Phys. 2011, 134 (5), 054316.

(39) Fantoni, A. C.; Caminati, W.; Favero, P. G. The SH Torsion Double Minimum Potential in Methylthioglycolate as Studied by Millimeterwave Free Jet Absorption Spectroscopy and Ab Initio Investigations. J. Mol. Spectrosc. 1996, 176 (2), 364-368.

(40) Nguyen, H. V. L.; Stahl, W.; Kleiner, I. Structure and Rotational Dynamics of Methyl Propionate Studied by Microwave Spectroscopy. Mol. Phys. 2012, 110 (17), 2035-2042.

(41) Ruoff, R. S.; Klots, T. D.; Emilsson, T.; Gutowsky, H. S. Relaxation of Conformers and Isomers in Seeded Supersonic Jets of Inert Gases. J. Chem. Phys. 1990, 93 (5), 3142-3150.

(42) Espinosa, E.; Molins, E.; Lecomte, C. Hydrogen Bond Strengths Revealed by Topological Analyses of Experimentally Observed Electron Densities. Chem. Phys. Lett. 1998, 285 (34), 170-173.

(43) Kisiel, Z. Least-Squares Mass-Dependence Molecular Structures for Selected Weakly Bounds Intermolecular Clusters, J. Mol. Spectrosc., 2003, 218, 58-67.

(44) Kisiel, Z. Evaluation Of Internal From Cartesians, EVAL Code, PROSPE-Programs For Rotational Spectroscopy. http://info.ifpan.edu.pl/ kisiel/prospe.htm (accessed July 10, 2019).

(45) Alemán, C.; Casanovas, J.; Zanuy, D.; Hall, H. K. Systematic Evaluation of the Conformational Properties of Aliphatic $\omega$-Hydroxy Acids. J. Org. Chem. 2005, 70 (8), $2950-2956$. 


\section{TOC Graphic}

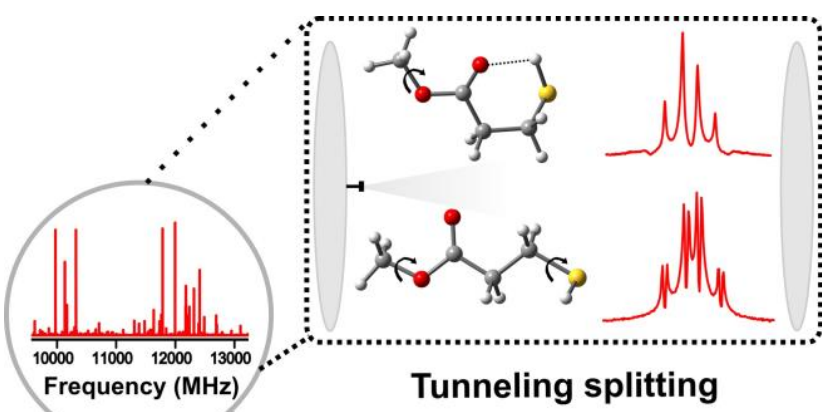

